
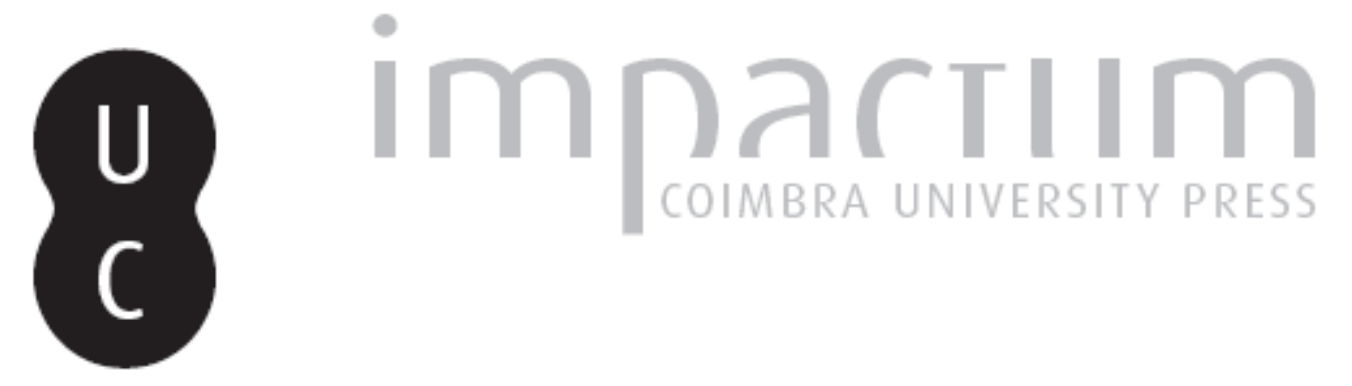

\title{
Acidentes laborais em Coimbra de 1930 a 1935
}

Autor(es): $\quad$ Santos, Mónica da Conceição Rodrigues dos

Publicado por: Imprensa da Universidade de Coimbra

URL persistente:

URI:http://hdl.handle.net/10316.2/40968

DOI:

DOI:https://doi.org/10.14195/1645-2259_16_18

Accessed : $\quad$ 26-Apr-2023 11:23:45

A navegação consulta e descarregamento dos títulos inseridos nas Bibliotecas Digitais UC Digitalis, UC Pombalina e UC Impactum, pressupõem a aceitação plena e sem reservas dos Termos e Condições de Uso destas Bibliotecas Digitais, disponíveis em https://digitalis.uc.pt/pt-pt/termos.

Conforme exposto nos referidos Termos e Condições de Uso, o descarregamento de títulos de acesso restrito requer uma licença válida de autorização devendo o utilizador aceder ao(s) documento(s) a partir de um endereço de IP da instituição detentora da supramencionada licença.

Ao utilizador é apenas permitido o descarregamento para uso pessoal, pelo que o emprego do(s) título(s) descarregado(s) para outro fim, designadamente comercial, carece de autorização do respetivo autor ou editor da obra.

Na medida em que todas as obras da UC Digitalis se encontram protegidas pelo Código do Direito de Autor e Direitos Conexos e demais legislação aplicável, toda a cópia, parcial ou total, deste documento, nos casos em que é legalmente admitida, deverá conter ou fazer-se acompanhar por este aviso.

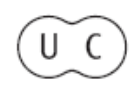




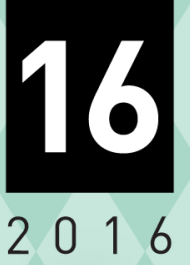

\section{Revista \\ de História \\ da Sociedade \\ e da \\ Cultura}




\title{
Acidentes laborais em Coimbra de 1930 a 1935
}

Labor accidents in Coimbra from 1930 to 1935

\author{
Mónica da Conceição Rodrigues dos Santos \\ Doutoranda em História \\ Universidade de Coimbra - CHSC \\ monica_ms@sapo.pt
}

Texto recebido em / Text submitted on: 04.04.2016

Texto aprovado em / Text approved on: 18.07.2016

Resumo: Este artigo tem como objetivo analisar os processos de acidentes de trabalho do Tribunal de Trabalho de Coimbra relativos ao período de 1930 a 1935 e, desse modo, refletir sobre as condições de trabalho dos sinistrados e as causas dos acidentes e respetivas consequências. Não esquecendo o momento em que os acidentes ocorrem, é de toda a conveniência contextualizar aspetos fundamentais para o seu aumento, particularmente nas primeiras décadas do século XX, como por exemplo o desenvolvimento industrial e a regulamentação legal associada aos tribunais do trabalho.

Palavras-chave: acidentes de trabalho, Coimbra, industrialização, Tribunal do Trabalho.

Abstract: This article aims to analyze the processes of the Coimbra Labor Court, for the period 1930-1935, and thus reflect on the victims working conditions and the causes of the accidents and their consequences. Not forgetting the time when accidents occur, it is important to contextualize key aspects to their increase, particularly in the beginning of the $20^{\text {th }}$ century, such as industrial development and legal regulations associated with the labor courts.

Keywords: Coimbra, industrialization, Labor Court, work accidents.

\section{Introdução}

Os acidentes laborais são, em Portugal, uma temática ainda pouco estudada, com exceção de alguns trabalhos pontuais sobre períodos cronológicos recentes. Desse modo se percebe porque os processos de acidentes no trabalho, sobretudo das décadas de 1920 e 1930, sejam documentação pouco explorada pela historiografia portuguesa.

Este texto tem por objetivo compreender os acidentes na primeira metade da década de 1930 em Coimbra, bem como os envolvidos nos processos. Para tal, é dividido em duas partes. Primeiramente, abordam-se os aspetos gerais da industrialização portuguesa, sendo posteriormente explicada a 
génese dos tribunais de trabalho e a respetiva evolução. Numa segunda fase estudam-se os sinistros ocorridos em Coimbra de 1930 a 1935, fazendo-se uma breve caracterização socioeconómica dos trabalhadores e empregadores e uma rápida análise das relações entre os intervenientes através dos conflitos expressos nos processos.

\section{Industrialização portuguesa: aspetos gerais}

A evolução técnica e científica é, em grande medida, responsável pelo aumento significativo dos acidentes no local de trabalho. Ao longo do século XIX a fábrica torna-se a "forma unificada de organização da produção industrial, com recurso à energia inanimada, à máquina e a trabalhadores" (Cardim 2005: 75) com diferentes especializações e valências, o que permitia uma organização laboral totalmente diferente daquela a que os trabalhadores estavam habituados, levando a excessos por parte dos empregadores e a más condições do local de trabalho.

Embora o disforme e lento desenvolvimento industrial nacional, as pequenas indústrias de características familiares iam dando lugar a fábricas de maior envergadura. A procura de mão-de-obra barata é uma constante e mulheres e crianças eram a força de trabalho mais explorada e com piores salários. Admitia-se que "o aperfeiçoamento da mecânica" permitia "aos menores conduzir" as máquinas e as mulheres, "dotadas de uma grande habilidade manual, igualavam-se, na produção, aos homens" sendo "mão-de-obra dócil, disciplinada, obedecendo sem discussão, cedendo a trabalhar horas extraordinárias, submissa, pronta para todos os sacrifícios", com um salário muito inferior ao do homem (Instituto 1928: 49).

As exigências por uma melhor condição do trabalho, melhores salários e horários regulares de oito horas, foram uma preocupação crescente dos operários. Desta forma, os operários precisavam de algum organismo que os representasse na luta por melhores condições. A este papel estavam vinculados, inicialmente, as confrarias e irmandades religiosas que respeitavam maioritariamente os "aspetos culturais, em detrimento do aspeto material da vida dos operários” (O Movimento 1977: 10), surgindo, posteriormente, as Associações Mutualistas com caráter protetor perante estes trabalhadores, defendendo-os na velhice, doença e desemprego.

Após a década de 1910 a difusão da energia a vapor encontrava-se consolidada, permitindo que se desenvolvessem algumas indústrias específicas - caso das indústrias químicas da CUF (Rosas 1994: 873), todavia a indus- 
trialização ocupava uma posição secundária em relação ao setor agrícola (Rosas, Rollo 2010: 235-237). O desenvolvimento industrial é, no entanto, bloqueado por diversos fatores dos quais se poderão destacar: ineficácia do desenvolvimento técnico de materiais e infraestruturas; preparação inadequada dos operários; falta de investimentos; escassez de algumas matérias-primas e combustíveis; própria concorrência externa (Mendes 1998: 365).

A regulamentação do direito à greve, logo em 1910, dececionou o operariado em relação à República. Os movimentos grevistas nos anos seguintes sofreram repressões elevadas, sendo inclusive encerrada a Casa Sindical (Rosas, Rollo 2010: 157-158). Os trabalhadores organizados consideravam que as medidas legais promovidas pela República, referentes às questões sociais, eram insuficientes, embora tenham acontecido. Podem ser destacados os decretos que implementaram o descanso semanal obrigatório, em 1911, ou a lei $\mathrm{n}^{\circ} 83$, de 1913 , sobre acidentes de trabalho, que será referida neste artigo. Em 1919 é aprovado um conjunto de medidas realmente significativo, desde logo o decreto no 5516, que estabelece o limite de oito horas de trabalho diário, e decretos relativos aos seguros sociais obrigatórios na doença, nos desastres laborais, na velhice e invalidez, sendo organizado o Instituto de Seguros Sociais Obrigatórios e de Previdência (Rosas, Rollo 2010: 159).

Em Portugal durante os primeiros anos do Estado Novo as iniciativas provenientes do Governo "eram ainda pouco consistentes" (Rollo 1996: 460), não existindo medidas legais que beneficiassem o desenvolvimento industrial até 1937 (Rosas 1996).

Embora a indústria conimbricense se encontrasse dispersa pelo concelho, havia, em 1930, um aglomerado significativo na Baixa da cidade, devido à proximidade com o rio e com as linhas férreas construídas nos finais do século XIX (Mendes 1984: 427). Todavia, a associação intrínseca da cidade com a Universidade forçava o predomínio dos serviços e estabelecimentos comerciais ${ }^{1}$ em detrimento das indústrias, que tinham um caráter familiar, artesanal e de dimensão reduzida. É predominante a indústria ligada à transformação têxtil, produção de bebidas, de que é exemplo a Fábrica da Cerveja Topázio, e massas alimentícias, como a Fábrica Triunfo.

No entanto, existe ainda um elevado número de indústrias relacionadas com a madeira e a construção civil e, embora não seja um centro industrial particularmente desenvolvido, é um polo atrativo para as populações mais rurais do centro norte do país.

Segundo o Boletim de Trabalho Industrial, de 1932 a 1935, mais de metade dos registos oficiais são referentes a comércios, sobretudo tabernas, mercearias e lojas variadas. 


\section{Os Tribunais de Trabalho: génese e evolução}

O desenvolvimento industrial "torna mais gritantes as injustiças dos desastres no trabalho" ${ }^{2}$, situação que obrigou o Estado a desenvolver mecanismos que protegessem o operariado e regulassem as indústrias, sendo, por esse motivo, criados, pela carta de lei de 14 de agosto de 1889, os Tribunais de Árbitros Avindores. O decreto autoriza a criação de tribunais nos centros industriais mais importantes, quando requerido por eles ou pelas corporações administrativas, ficando a indicação que Lisboa - cujo tribunal é criado em 1893 - e o Porto poderiam ter mais do que um.

A estes tribunais ficava incumbida a mediação de conflitos contratuais, respeitante a salários, horários, mão-de-obra, indemnizações e outros assuntos que envolvessem patrões e operários. Competia ao tribunal, para além de receber e mediar reclamações relativas ao serviço ou contrato de trabalho por parte dos funcionários, vigiar o cumprimento e a execução de leis e regulamentos respeitantes à indústria. Tinha como objetivo repreender as condutas, quer de empregadores, quer de empregados, quando alguma das partes esquecia as "boas normas de equidade, doçura, respeito e obediência, que devem presidir às relações entre uns e outros” (Collecção 1889: 371).

$\mathrm{O}$ crescimento da indústria chama cada vez mais mão-de-obra que não se encontrava protegida em caso de acidentes. $\mathrm{O}$ número de desastres obrigou o governo a reconsiderar as leis referentes à indústria assim como a ponderar a possibilidade de um órgão judiciário focado nestas questões. A 24 de julho de 1913 surge a lei no 83 , que vem dar impulso ao direito dos trabalhadores, por conta de outrem, de terem acesso a assistência médica, medicamentos e indemnização em caso de desastre no trabalho.

Esta lei é considerada uma das "melhores iniciativas da República" no que respeitava as classes trabalhadoras ${ }^{3}$ e o embrião do Estado Providência em Portugal (Pereira 2013: 1240-1245). Neste diploma ficava explícito que o acidente seria "toda a lesão externa ou interna e toda a perturbação nervosa ou psíquica, que resultem da ação duma violência exterior súbita, produzida durante o exercício profissional" e também "as intoxicações agudas produzidas durante e por causa do exercício profissional, e as inflamações das bolsas serosas profissionais" .

2 Arquivo da Universidade de Coimbra (AUC), Tribunal do Trabalho de Coimbra (TTC), Acidentes de Trabalho (AT), Caixa 206, Processo 2412/656, fl. 77.

3 Diário do Governo, $1^{\text {a }}$ série, no 98, Lisboa: Imprensa Nacional, 10 de maio de 1919, p. 1034.

4 Diário do Governo, Lisboa: Imprensa Nacional, no 171, 24 de julho de 1913, p. 2754. 
A execução deste corpo legislativo foi, no entanto, morosa. Desse modo é publicado, a 9 de março de 1918, o decreto no 4288, que vem agrupar, num só diploma, toda a legislação sobre desastres de trabalho porque esta estava "dispersa por diversos diplomas, o que muito dificulta a sua fiel execução"s.

O decreto é também responsável por organizar os Tribunais de Desastres no Trabalho, que, pela primeira vez, surgem com esta denominação no corpo legislativo. Passam a ter como competência conhecer e julgar "todas as questões suscitadas na aplicação da lei no 83, de 24 de julho de 1913” e ainda todos os autos de não conciliação entre as partes, participações feitas pelos sinistrados, indemnizações efetuadas ilegalmente, qualquer transgressão "de que tenha tido conhecimento pelos interessados e pelos fiscais" ou "tomar as providências convenientes nos casos de falecimento de qualquer sinistrado, comunicado pelo hospital"6.

No que respeitava a organização do tribunal, uma das principais diferenças com os Tribunais de Árbitros Avindores consistia na obrigatoriedade de os Presidentes e Vice-Presidentes serem bacharéis em Direito. Porém, devido à "precária situação do Tesouro Público", ficavam suprimidos os lugares de juízes à medida que iam caducando os contratos de três anos pelos quais eram nomeados, ficando o cargo entregue aos chefes de Circunscrição de Previdência Social, que podiam não possuir bacharelato (Instituto 1943: 142). O tribunal era incapaz de se impor como organismo judiciário tornando-se um "campo aberto ao deflagrar dos ódios então existentes entre patrões e operários", o que refletia "o predomínio do espírito de uma classe sobre o da outra” (Instituto 1943: 143).

A criação dos tribunais como os conhecemos, é aprovada pelo decreto-lei no 23053, a 23 de setembro de 1933, ficando sob o controlo do Subsecretariado de Estado das Corporações e Previdência Social, integrado no Ministério da Presidência, dependendo diretamente de Salazar.

Nesse mesmo dia é publicado o decreto-lei no 23048 que cria o Estatuto do Trabalho Nacional (ETN) onde se definem os "novos princípios da ordem social do Estado Novo” (Correia 1999: 551). Na Constituição Portuguesa, aprovada por plebiscito nacional a 19 de março de 1933, encontra-se especificado, no artigo 290, que a "organização económica da Nação deverá realizar o máximo de produção e riqueza socialmente útil, e estabelecer uma vida coletiva de que resultem poderio para o Estado e justiça entre os cidadãos"

\footnotetext{
Diário do Governo, 1a Série, Lisboa: Imprensa Nacional, no 111, 22 de maio de 1918, p. 795.

Diário do Governo, 1a Série, Lisboa: Imprensa Nacional, no 111, 22 de maio de 1918, p. 810-811.

Diário do Governo, $1^{\text {a Série, no }}{ }^{14}$, Lisboa: Imprensa Nacional, 19 de janeiro de 1924, p. 38.
} 
(Constituição 1971: 9). Daqui depreende-se não apenas o cunho unitário da sociedade, mas, tal como está explícito no Estatuto, a obrigação e o direito do Estado regular a vida económica e social do país. O ETN é um dos diplomas que marca o "início da definição corporativa do Estado Novo", tendo um papel fundamental na contenção do sindicalismo livre e na aproximação com o trabalho e o capital por parte do Estado (Valente 1996: 319-320).

No capítulo relativo ao trabalho é esclarecido que este, "em qualquer das suas formas legítimas, é para todos os portugueses um dever de solidariedade social" e a todos deveria ser garantido o direito ao trabalho e ao salário "humanamente suficiente" sem haver lugar para discriminações de ordem "económica, jurídica e moral da sociedade". No caso das mulheres e dos menores, todo o trabalho exercido fora do domicílio teria de ser regulado de maneira particular atendendo às "exigências da moral, da defesa física, da maternidade, da vida doméstica, da educação e do bem social", não sendo por isso abrangidos no decreto. A regulação do trabalho proibido a mulheres e menores aparece apenas um ano mais tarde, a 15 de setembro, com o decreto no 24535 .

No que respeita à execução da lei, é legislado que os juízes devem ser independentes e que apenas da sua consciência depende julgar a ação, quando não há qualquer possibilidade de conciliação entre as partes ${ }^{10}$. Contudo, fica ainda decretado que junto aos juízes deve existir sempre um agente do Ministério Público que servirá como fiscal da lei e "protetor oficioso dos trabalhadores" e será o elo de ligação entre o Estado e o Tribunal ${ }^{11}$, o que vai retirar independência aos juízes.

Na verdade, o agente, escolhido de entre os delegados do Instituto Nacional do Trabalho e Previdência ${ }^{12}$, vai auxiliar o juiz a seguir a lei e poderá interceder pelo sinistrado quando este não apresentar defesa contra contestações por parte de empregadores ou seguradoras.

8 Diário do Governo, $1^{\text {a }}$ série, no 217, Lisboa: Imprensa Nacional, 23 de setembro de 1933, p. 1656.

9 Diário do Governo, 1a série, no 217, Lisboa: Imprensa Nacional, 23 de setembro de 1933, p. 1657.

10 O artigo $29^{\circ}$ do decreto-lei no 23053, de 23 de setembro de 1933, esclarece precisamente que os "juízes do trabalho são responsáveis civil, criminal e disciplinarmente, nos termos da lei, pelas decisões que proferirem" sendo a exceção consignada no artigo $120^{\circ}$ da Constituição, em que é referido serem os “juízes irresponsáveis nos seus julgamentos”. Ver Diário do Governo, $1^{\text {a }}$ série, n 217, Lisboa: Imprensa Nacional, 23 de setembro de 1933, p. 1673 e Constituição 1971: 31.

11 Diário do Governo, $1^{\text {a }}$ série, no 217, Lisboa: Imprensa Nacional, 23 de setembro de 1933, p. 1658.

12 O Instituto (INTP) é criado no mesmo diploma que origina os tribunais, a 23 de setembro de 1933. Tem como objetivo assegurar a execução das leis do trabalho e integrar os trabalhadores na organização corporativa prevista no Estatuto do Trabalho Nacional. 
A evolução jurídica portuguesa, relativa ao direito laboral, não surge isolada. Internacionalmente foram surgindo, logo a partir de meados do século XIX, iniciativas com vista ao melhoramento da vida dos operários. As medidas legislativas são respostas às necessidades sentidas em todos os países industrializados ou em vias de industrialização. Quando na Conferência de Berlim (1884-85) se colocaram em evidência determinados problemas como o descanso semanal ou o trabalho infantil, Portugal assegurou, sem ter vinculado qualquer tipo de obrigatoriedade, a aprovação de legislação regulamentadora do trabalho industrial para mulheres e menores, bem como trabalho noturno, higiene no trabalho e descanso semanal (através do decreto de 14 de abril de 1891). Mais tarde é aprovada a inclusão, no tratado de Versalhes, da constituição da OIT, que regulariza estas questões.

\section{Desastres laborais em Coimbra}

De acordo com o artigo $1^{\circ}$ do decreto-lei no 938 de 9 de outubro de 1914 , sinistrado é todo aquele que, sendo assalariado e trabalhe em qualquer dos ramos industriais ou comerciais, for vítima de um desastre no trabalho, qualquer que seja a importância da lesão sofrida.

Para o presente estudo, foram analisados 558 processos correspondentes aos acidentes laborais ocorridos no distrito de 1930 a 1935. Desses, 31 (6\%) referem-se a mulheres e 527 (94\%) a homens.

Gráfico 1. Processos efetuados no Tribunal de Trabalho de Coimbra

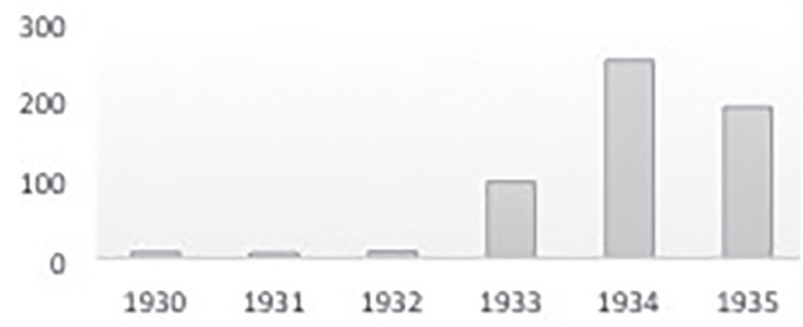

Fonte: AUC/TIC/AT/Caixas 202 a 234

Retira-se da análise do Gráfico 1 que, a partir de 1933, ocorre um crescimento abrupto de participações em relação aos anos anteriores. Esta evolução poderá, no entanto, não ser totalmente fidedigna devido a múltiplos fato- 
res, desde logo o incêndio de 1943 - ocorrido no edifício do Governo Civil, onde se situava então o tribunal - que destruiu vários processos e alguns registos. Para além disso existe a possibilidade de terem sido extraviados alguns processos sendo, desse modo, credível que a documentação enviada para o Arquivo da Universidade de Coimbra, local onde foi consultada, seja em número inferior à existente originalmente.

$\mathrm{O}$ aumento do número de participações de acidentes poderá ainda ser devido à difusão do papel dos tribunais, tal como dos deveres e direitos de empregadores e empregados, considerando que o número de processos, a nível nacional, é também crescente ao longo da década (Instituto 1943: $152)^{13}$.

Fica claro que os acidentes envolvendo homens é significativamente superior àqueles que envolvem mulheres, concordante com o facto de o trabalho feminino corresponder apenas a cerca de $27 \%$ da totalidade da população ativa nacional durante o período estudado (Baptista 1999: 186). A ideologia do Estado Novo reservava-lhe o papel de dona de casa e mãe, estando também associado o trabalho na agricultura e em algumas indústrias artesanais, sempre em prol do bem-estar familiar, ficando, por isso, vedadas algumas atividades profissionais, desde logo as indústrias com materiais voláteis e com elevados índices de toxicidade (Instituto 1943: 99-101). É ainda possível que muitos acidentes envolvendo mão-de-obra feminina não fossem participados, quer por receio de se perder o emprego ou por não ser atribuída gravidade à situação.

\section{Os sinistrados e os sinistros}

A partir da análise dos processos, afere-se que os sinistrados residiam maioritariamente no distrito de Coimbra, havendo apenas algumas exceções que, na sua totalidade, não ultrapassam os $3 \%$ dos casos (18 processos). Quanto aos dados relativos à naturalidade, é possível apreender migrações internas, considerando que apenas 266 sinistrados (50,5\%) eram naturais do concelho de Coimbra. Por altura dos acidentes, $56 \%$ dos sinistrados residiam no concelho, sobretudo na zona da cidade, sendo aí que se encontrarem a maioria das indústrias.

13 De 1934 para 1935 são feitas mais 6512 participações, embora esse número principie a decair a partir desse ano. 
Quanto ao estado civil, 64,5\% das mulheres eram solteiras, indicando que a população feminina ativa diminuía consideravelmente após o casamento, situação que se coaduna com o papel reservado à mulher na sociedade estado-novista (Pimentel 2011: 54-79; Vaquinhas 2011: 118-157). Já os homens eram maioritariamente casados, contabilizando-se $59,4 \%$ na sua totalidade.

Os mais afetados pela sinistralidade laboral tinham entre 20 e 34 anos, embora a faixa etária mais jovem, entre os 15 e os 19 anos, tivesse bastante representatividade em ambos os géneros. É, portanto, fácil estabelecer uma ligação entre o estado civil dos acidentados e a sua idade, particularmente no caso das mulheres, bem como concluir que a inexperiência profissional pode ser determinante na sinistralidade laboral.

Apenas 154 (29,2\%) e 7 (22,6\%) de homens e mulheres, respetivamente, tinham filhos a seu cargo. A média de filhos estaria entre os dois e os três por família, situação concomitante com os dados apurados por Mário Leston Bandeira (Bandeira 1996: 366-369), que estabelecem que a nível nacional, de 1920 a 1940, ocorreu um crescimento de famílias com dois a quatro elementos em detrimento das famílias mais numerosas.

Relativamente aos homens sinistrados, sendo a indústria, especialmente a construção civil, o sector de atividade mais comum (34,7\%), as profissões são variadas havendo um maior número de trabalhadores com relativa especialização, como eletricistas e mecânicos. A falta de especialização e experiência poderá estar ligada à ocorrência de descuidos devido à má realização do serviço ou à distração, como aconteceu com Joaquim, de 22 anos, trabalhador dos serviços municipalizados de Coimbra, que sofreu um acidente em 1933, ficando com um hematoma na mão depois de lhe ter escorregado uma ferramenta de trabalho ${ }^{14}$. Este tipo de caso é comum, indicando que os acidentes são resultado sobretudo, segundo os processos, da casualidade e da distração dos trabalhadores do que propriamente dos locais de trabalho, embora não haja informação que explique as suas condições de higiene e segurança. Por outro lado, como as participações eram muitas vezes feitas pelas entidades patronais, as causas verdadeiras dos sinistros poderiam ser encobertas, podendo ficar o sinistrado com maior responsabilidade do que a merecida.

14 AUC/TTC/AT/Caixa 209/Processo 1071/830. 
Quadro 1. Sinistrados segundo o grupo socioprofissional ${ }^{15}$

\begin{tabular}{|l|c|c|c|c|c|c|}
\hline \multicolumn{1}{|c|}{ Grupo socioprofissional } & Homens & $\%$ & Mulheres & $\%$ & Total & $\%$ \\
\hline Comércio e seguros & 12 & $2,3 \%$ & 2 & $6,5 \%$ & 14 & $2,5 \%$ \\
\hline $\begin{array}{l}\text { Exploração da superfície do } \\
\text { solo }\end{array}$ & 46 & $8,7 \%$ & 3 & $9,7 \%$ & 49 & $8,8 \%$ \\
\hline Extração das matérias minerais & 5 & $0,95 \%$ & - & - & 5 & $0,9 \%$ \\
\hline Indústria & 316 & $59,96 \%$ & 22 & $70,9 \%$ & 338 & $60,6 \%$ \\
\hline Trabalhos domésticos & 1 & $0,2 \%$ & 2 & $6,5 \%$ & 3 & $0,5 \%$ \\
\hline Transportes & 106 & $20,1 \%$ & 2 & $6,5 \%$ & 108 & $19,4 \%$ \\
\hline Vive dos rendimentos & 3 & $0,6 \%$ & - & - & 3 & $0,5 \%$ \\
\hline Sem informação & 38 & $7,2 \%$ & - & - & 38 & $6,8 \%$ \\
\hline Total & 527 & $100 \%$ & 31 & $100 \%$ & 558 & $100 \%$ \\
\hline
\end{tabular}

Fonte: AUC/TTC/Acidentes de Trabalho/Caixa 202 a 234.

No caso feminino, a maioria dos incidentes estão relacionados com a indústria, como é visível no quadro 1 . Nesta indústria são comuns as perfurações por agulhas, como aconteceu com Guilhermina, de 24 anos, e com Mariana, de 19, operárias da Ideal Lda., sendo imediatamente assistidas pelo médico da companhia seguradora Fidelidade ${ }^{16}$.

Segundo a designação usada nos processos, as quedas $(15,4 \%)$, os descuidos $(14,2 \%)$ e os acidentes provocados pelo contacto indevido com o material de trabalho $(14,6 \%)$ são as principais causas dos sinistros masculinos. No caso das sinistradas são comuns as quedas e as perfurações.

A maioria dos acidentes (92,2\%) não apresentam consequências permanentes, porém há exceções. Álvaro foi eletrocutado em 1934, e a empresa para a qual trabalhava - Companhia de Papel de Góis - foi acusada de ter realizado a instalação elétrica de forma ilegal ${ }^{17}$ sendo chamada a Administração Geral dos Serviços Hidráulicos e Elétricos para proceder a um inquérito, de modo a averiguar a situação em que ocorreu o acidente.

Embora a família do sinistrado tenha recebido as indemnizações e se tenha provado que existiam más condições de trabalho, nenhuma entidade, estatal ou particular, impôs a renovação das instalações da fábrica. A entidade empregadora e a empresa que fez a instalação elétrica ficaram apenas obriga-

\footnotetext{
15 Nomenclaturas usadas segundo o Recenseamento Geral da População de 1930.

16 AUC/TTC/Acidentes de Trabalho/Caixa 213/Processo 1138 e Caixa 214/ Processo 1208, respetivamente.

17 AUC/TTC/Acidentes de Trabalho/Caixa 212/Processo 1124/933.
} 
das, por ordem do Ministério das Obras Públicas e Comunicações, a pagar uma multa e a legalizar a instalação.

No caso dos homens, os principais danos reportam-se a contusões $(21,6 \%)$ e a fraturas $(10,8 \%)$, sendo que escoriações, queimaduras, traumatismos diversos e úlceras são também habituais (21,6\% dos casos). Os membros superiores são a zona do corpo mais atingida pelos acidentes (36,4\%). As mulheres apresentavam sobretudo lesões nos dedos, devido a perfurações por agulhas. No período estudado, 49 (8,8\%) dos sinistrados ficaram permanentemente incapacitados. Destes, apenas 24 necessitaram da intervenção direta do tribunal e, consequentemente, da sentença, e 17 reportam-se a processos em que já tinha havido, por altura da participação, acordo entre o acidentado e a seguradora, sendo desse modo apenas necessária a homologação do processo.

Como fica visível no quadro 2, se associarmos os processos que envolvem sentenças ou que são arquivados por caducidade, apenas $18 \%$ se reportam a processos em que não é feito acordo ou conciliação com empregadores e seguradoras. Embora todos os processos necessitem de homologação, apenas uma pequena percentagem requer a intervenção efetiva do tribunal, considerando que 55\% foram resolvidos por meio de acordos com a seguradora.

Quadro 2. Resultado dos Processos

\begin{tabular}{|l|c|c|c|c|c|c|}
\hline \multicolumn{1}{|c|}{ Resultado } & Homens & $\%$ & Mulheres & $\%$ & Total & $\%$ \\
\hline Acordo com seguradora. & 283 & $54 \%$ & 22 & $71 \%$ & 305 & $55 \%$ \\
\hline Conciliação com empregador $^{\prime}$ & 148 & $28 \%$ & 4 & $13 \%$ & 152 & $27 \%$ \\
\hline Outros resultados $^{18}$ & 96 & $18 \%$ & 5 & $16 \%$ & 101 & $18 \%$ \\
\hline Total & 527 & $100 \%$ & 31 & $100 \%$ & 558 & $100 \%$ \\
\hline
\end{tabular}

Fonte: AUC/TTC/Acidentes de Trabalho/Caixa 202 a 234.

É no trabalho masculino que se encontram as atividades mais especializadas e, por consequência, mais bem remuneradas, sendo percetível que a alfabetização poderia significar melhoria de salário, como é observável no quadro 3, havendo, no entanto, exceções. Os ajudantes e aprendizes, jovens entre os 11 e os 16 anos, tinham salários inferiores mesmo sabendo ler, sendo a média salarial de $3 \$ 43$.

18 Em outros resultados incluem-se os processos que foram arquivados devido à inércia das partes e os que foram sujeitos a julgamento. 
Quadro 3. Nível de alfabetização e relação com média salarial ${ }^{19}$

\begin{tabular}{|l|c|c|c|c|c|c|c|c|}
\hline & \multicolumn{3}{|c|}{ Homens } & \multicolumn{3}{c|}{ Mulheres } & \multicolumn{2}{c|}{ Total } \\
\hline Sabe ler & & $\%$ & Média salarial & & $\%$ & Média salarial & & $\%$ \\
\hline Sim & 283 & $53,7 \%$ & 10,04 & 3 & $9,7 \%$ & 5,95 & 286 & $51,3 \%$ \\
\hline Não & 214 & $40,6 \%$ & 8,09 & 26 & $83,9 \%$ & 4,08 & 240 & $43 \%$ \\
\hline Indefinido & 30 & $5,7 \%$ & 6,91 & 2 & $6,5 \%$ & 5,00 & 32 & $5,7 \%$ \\
\hline Total & 527 & $100 \%$ & 9,13 & 31 & $100 \%$ & 4,32 & 558 & $100 \%$ \\
\hline
\end{tabular}

Fonte: AUC/TTC/Acidentes de Trabalho/Caixa 202 a 234.

Os dados apurados demonstram que $286(51,3 \%)$ da totalidade dos sinistrados sabiam ler. Todavia, enquanto, no caso dos homens, mais de metade são alfabetizados, as mulheres são esmagadoramente analfabetas. Existe uma disparidade salarial entre homens e mulheres.

As diversidades salariais estão ainda associadas ao tipo de serviço efetuado. Um operário fabril recebia cerca de $7 \$ 89$ diariamente, sendo menos do que um gerente comercial - que poderia ganhar até 30\$00 diários - mas tinha melhor salário do que um agricultor, que auferia em média $6 \$ 08$ por dia $^{20}$. Um serralheiro, como Albano, poderia chegar a ganhar $25 \$ 00$ diários $^{21}$ em 1933, embora a média se situasse nos $11 \$ 00$. Os empregados não especializados da construção civil e os aprendizes eram os piores remunerados ${ }^{22}$. No caso das mulheres, o salário mais elevado - $12 \$ 66$ diários - pertencia a Belmira, funcionária dos correios, enquanto os salários mais baixos correspondiam às trabalhadoras rurais e às operárias fabris. Numa fábrica de lanifícios, por exemplo, uma mulher ganhava, em média, $4 \$ 00$ diários. Já um homem que realizasse o mesmo serviço recebia, na mesma fábrica, até $10 \$ 00$ diários ${ }^{23}$.

Nos trabalhos poucos especializados não se pode deduzir que os indivíduos alfabetizados eram melhor remunerados em relação aos restantes. Esta conclusão aplica-se às profissões agrícolas e à maioria das indústrias. Exemplo representativo deste tipo de situação é o caso de Manuel e Joaquim, ambos operários fabris não especializados na fábrica Ideal Lda. Manuel, de 30 anos, não sabia ler, e ganhava 10\$ diários, enquanto Joaquim, de 21 anos,

19 As médias foram calculadas considerando todas as profissões apresentadas nos processos.

20 As médias são relativas às profissões assinaladas (operário fabril, gerente comercial e agricultor).

21 AUC/TTC/AT/Caixa 205/Processo 1086/596.

22 Por exemplo, o caso de Domingos, aprendiz de serralheiro, que ganha diariamente 1\$80: AUC/ TTC/AT/Caixa 209/Processo 1053/847.

23 Médias calculadas em funcionários da fábrica Ideal Lda de 1931 a 1935. 
ganhava $4 \$ 50$ por $\operatorname{dia}^{24}$. A diferença salarial poderia estar associada à experiência profissional.

Existiam ainda outras formas de pagamento salarial entre os quais se incluem remunerações em bens variados. No caso dos criados, estes tinham direito a roupa, comida e cama, como é o caso António, de 12 anos, criado de servir, que residia em casa dos patrões ${ }^{25}$. Alguns trabalhadores agrícolas, como Manuel, na prática não tinham contrato de trabalho: varejava castanheiros por favor e em troca de uma onça de tabaco ${ }^{26}$. No caso de Maria que, para complementar os $2 \$ 00$ diários que recebia na fábrica de malhas, teve de recorrer ao trabalho na construção civil, num local onde trabalhavam "umas duzentas mulheres” e cujo serviço era pago em senhas de alimentação ${ }^{27}$.

\section{Algumas considerações sobre as entidades responsáveis}

Como é esclarecido pelo quadro 4, as entidades responsáveis pelos sinistrados são maioritariamente empresas e empregadores particulares, totalizando 63\% dos processos analisados. Já o Estado e os Municípios eram legalmente responsáveis por $36 \%$ dos sinistros.

Quadro 4. Distribuição dos empregadores por entidades

\begin{tabular}{|l|c|c|c|c|c|c|}
\hline & Homens & $\%$ & Mulheres & $\%$ & Total & $\%$ \\
\hline Empresa & 132 & $25 \%$ & 20 & $65 \%$ & 152 & $27 \%$ \\
\hline Estado & 120 & $23 \%$ & 2 & $6 \%$ & 122 & $22 \%$ \\
\hline Município & 78 & $15 \%$ & - & - & 78 & $14 \%$ \\
\hline Particular & 193 & $36 \%$ & 9 & $29 \%$ & 202 & $36 \%$ \\
\hline Trabalhador por conta própria & 4 & $1 \%$ & - & - & 4 & $0,7 \%$ \\
\hline Total & 527 & $100 \%$ & 31 & $100 \%$ & 558 & $100 \%$ \\
\hline
\end{tabular}

Fonte: AUC/TTC/Acidentes de Trabalho/Caixa 202 a 234

Nos casos em que o Estado era o empregador, a responsabilidade pelos sinistros não é assumida por nenhuma seguradora. O Estado teria, assim, de indemnizar os seus funcionários. Considerando que todos os processos que envolviam estes sinistrados eram relativamente breves e resultavam em

\footnotetext{
24 AUC/TTC/AT/Processo 1203/1006 e 1825/1377, respetivamente.

25 AUC/TTC/AT/Processo 1074/827.

26 AUC/TTC/AT/Caixa 213/ Processo 1199/1002.

27 AUC/TTC/AT/Caixa 205/Processo 926/570.
} 
conciliação, é possível discernir que os funcionários não reclamavam das indemnizações conseguidas, nem o Estado criava barreiras ao seu pagamento. Nestes casos, a mediação do tribunal era mínima, senão mesmo inexistente, limitando-se a cumprir a burocracia. No caso das entidades municipais os processos são ligeiramente diferentes. As Câmaras Municipais e os Serviços Municipalizados, que empregavam $14 \%$ da totalidade dos sinistrados, tinham todo o seu pessoal segurado.

Os processos de acidentes envolvendo o Estado ou os Municípios eram reduzidos - contabilizavam no máximo dez páginas - e as partes conciliavam-se com rapidez e facilidade, considerando que nenhum desses processos demorou mais do que dois anos a concluir.

No caso de os empregadores particulares e empresas a duração dos processos variava consideravelmente. Existem processos que se arrastam por mais de cinco anos, por razões várias: a burocracia do tribunal obriga a que as tentativas de conciliação exijam muita documentação que demora a instruir; os processos com julgamento e sentença são, por si só, mais morosos.

No caso de o empregador não ter constituído seguro, era obrigado a depositar, na Caixa Geral de Depósitos, Crédito e Previdência, uma caução, correspondente ao cálculo da desvalorização, à ordem da Inspeção de Seguros. Caso isso não fosse possível, avançava-se para a averiguação de bens penhoráveis. No caso de não ter meios de pagamento nem bens penhoráveis, o tribunal enviava o resultado do processo à Inspeção de Seguros, não sendo possível depreender, apenas pelo estudo dos processos, se esses sinistrados recebiam as pensões em causa por o tribunal os arquivar imediatamente ${ }^{28}$.

Das 202 participações envolvendo entidades particulares, 33,9\% reportam-se a patrões que não tinham os seus trabalhadores cobertos por seguro. Desses, apenas 19 chegaram a uma conciliação promovida pelo tribunal. Quando não havia consenso, os sinistrados ficavam à mercê das "raras qualidades de inteligência do ilustre juiz" que, segundo um advogado, era cuidadoso e "preocupado exclusivamente em fazer justiça" 29 .

As seguradoras promoviam acordos entre as partes, quando se tratava de lesões temporárias, pagando os dois terços do salário por dia de incapacidade $^{30}$, sendo a participação do acidente apenas uma formalidade. No caso de os sinistrados ficarem com danos físicos permanentes, as seguradoras ten-

28 AUC/TTC/AT/Caixa 208/Processo 1010/819 e Caixa 216/Processo 1179/74.

29 AUC/TTC/AT/Caixa 213/Processo 4473/992, fl. 156.

30 O pagamento deste tipo de indemnização estava estipulado no artigo 6º alínea c, da Lei no 83 de 24 de julho de 1913. 
tavam que a pensão a pagar fosse mínima, chegando a declinar determinados valores de incapacidade ${ }^{31}$ por os considerarem elevados. Dos acidentes protegidos por seguradora, 349 no seu total, apenas em 35 casos não se chegou a acordo, o que parece significar que as seguradoras tendiam a solucionar os conflitos de forma amigável, não havendo um número significativo de reclamações.

O tempo da incapacidade era particularmente duro para a família dos acidentados. Sebastião, um sinistrado da construção civil, chega mesmo a pedir ao juiz que "se digne providenciar, conforme for de justiça, visto [...] ser pobre e ter filhos a sustentar" porque o processo se arrastou e a seguradora não tinha pago a indemnização correspondente aos dias de incapacidade ${ }^{32}$.

Enquanto os processos se alongavam por não existir consenso entre as partes, ou por não ser aceite a sentença do tribunal, os sinistrados e as suas famílias tentavam sobreviver como podiam, aceitando, na maioria, o que lhe seria imposto. Já as seguradoras recorriam das sentenças esperando que as novas decisões lhes permitissem pagar menos indemnizações, demonstrando falta de interesse com o bem-estar dos sinistrados, que, em última análise, deveriam ser os maiores beneficiadores da atividade seguradora.

\section{Conclusão}

As questões relativas a desastres laborais são cada vez mais pertinentes, consequência do desenvolvimento industrial, que oferece oportunidades de trabalho a um número cada vez maior de pessoas, e também da progressiva consciencialização da necessidade de proteção face aos riscos profissionais. Para regular os conflitos são criados, desde o século XIX, tribunais especializados na questão laboral, que vão evoluindo consoante o desenvolvimento do próprio mercado de trabalho e da constante necessidade de melhorarem o seu campo de ação.

Se a causa do acidente era, enfim, passível de receber diferentes interpretações, resultado, inclusive, do incompetente preenchimento das participações, já no caso das consequências dos sinistros, a situação mudava, por estas poderem ser quantificadas e sobre elas ser possível realizarem-se cálculos que, não só as interpretam, como também as qualificam.

\footnotetext{
31 Os valores de incapacidade permanente eram avaliados por médicos que se guiavam pela tabela de desvalorização Lucien Mayet, não havendo uma tabela nacional até 1960.

32 AUC/TTC/AT/Caixa 214/Processo 1224/1026.
} 
Compreende-se que determinadas profissões reúnem tendencialmente trabalhadores de uma específica faixa etária e estado civil. Os mais jovens trabalhavam preferencialmente na indústria, sendo os principais sinistrados, sugerindo que esta faixa etária seria aquela que teria maior volume de população ativa, bem como menos experiência laboral.

É percetível que, de um modo geral, os empregadores e as seguradoras não colocam entraves aos procedimentos legais, como confirmado pela elevada percentagem de processos concluídos rapidamente e terminados em conciliação. Porém, a inércia das partes, no caso dos processos caducados, poderá significar desconhecimento, por parte do sinistrado, do papel do tribunal. Desse modo, era levado a resolver pessoalmente, com o empregador, os conflitos advindos do sinistro. Outra questão que terá de se ter em consideração é o possível medo, por parte do sinistrado, de sofrer represálias. Todavia, nenhuma das hipóteses poderá ser comprovada pela simples leitura dos processos, considerando que o tribunal tinha limitações.

\section{Bibliografia}

\section{Fontes}

Arquivo da Universidade de Coimbra/Tribunal do Trabalho de Coimbra/Acidentes de Trabalho/Caixas 202 a 234.

Collecção Official de Legislação Portuguesa: Imprensa Nacional, 1889 a 1891.

Diário do Governo, Lisboa: Imprensa Nacional, 1907-1913.

Diário do Governo, 1ª Série, Lisboa: Imprensa Nacional, 1914-1937.

\section{Estudos}

BANDEIRA, Mário Leston (1996). Demografia e modernidade: família e transição demográfica em Portugal. Lisboa: INCM.

BAPTISTA, Virgínia do Rosário (1999). As mulheres no mercado de trabalho em Portugal: representações e quotidianos (1890-1940). Lisboa: CIDM.

CARDIM, José Casqueiro (2005). Do ensino industrial à formação profissional. As políticas públicas de qualificação em Portugal. Vol. 1. Lisboa: Universidade Técnica de Lisboa, Instituto Superior de Ciências Sociais e Políticas.

CORREIA, Luís Brito (1999), “Direito do Trabalho”, in Maria Filomena Mónica, António Barreto (coord.), Dicionário de História de Portugal. Suplementos. Vol. 7. Lisboa: Figueirinhas. 
MENDES, José Amado (1984). A área económica de Coimbra, estrutura e desenvolvimento industrial, 1867-1927 (tese de doutoramento policopiada).

MENDES, José Amado (1998) “Etapas e limites da industrialização”, in José Mattoso (dir.), Luís Reis Torgal, João Lourenço Roque (coord.), História de Portugal. O Liberalismo (1807-1890). Vol. 5. Lisboa: Estampa.

Ministério do Emprego e da Segurança Social (1994). Organização Internacional do Trabalho (1919-1994), Lisboa: Direção de Serviços de Informação Científica e Técnica.

O Movimento Operário em Portugal: desde 1834 a 1933. Lisboa: Sindicato dos Eletricistas do Sul, 1977.

NUNES, Américo et al. (2011). Contributos para a história do movimento operário e sindical: das raízes até 1977. Vol. 1. Lisboa: CGTP.

PEREIRA, Miriam Halpern (2013). “Estado Providência”, in Maria Fernanda Rollo (coord.), Dicionário de História da I República e do Republicanismo. Vol. 1. Lisboa: Assembleia da República - Divisão de Edições, 1240-1245.

PIMENTEL, Irene Flunser (2011). A cada um o seu lugar. A política feminina do Estado Novo. Lisboa: Temas e Debates/Círculo de Leitores.

ROLLO, Maria Fernanda (1996). “Indústria/Industrialização” in Fernando Rosas (dir.), Dicionário de História do Estado Novo. Vol. 1. Lisboa: Círculo de Leitores.

ROSAS, Fernando (1994). "Estado Novo e desenvolvimento económico (anos 30 e 40): uma industrialização sem reforma agrária”, in Análise Social, 29 (128), 871-877.

ROSAS, Fernando (1996), O Estado Novo nos anos trinta: 1928-1939: elementos para o estudo da natureza económica e social do salazarismo. $2^{\text {a }}$ ed. Lisboa: Estampa.

ROSAS, Fernando (coord.) (1998). História de Portugal. Dir. José Mattoso. O Estado Novo (1926-1974). Vol. 7. Lisboa: Estampa.

ROSAS, Fernando; ROLLO, Maria Fernanda (coord.) (2010), História da Primeira República Portuguesa. Lisboa: Edições Tinta-da-China.

VALENTE, José Carlos (1996). “Estatuto do Trabalho Nacional”, in Fernando Rosas (dir.), Dicionário de História do Estado Novo. Lisboa: Círculo de Leitores.

VAQUINHAS, Irene (2011). “A família, essa «pátria em miniatura»”, in José Mattoso (dir.); Irene Vaquinhas (coord.), História da vida privada em Portugal: A época contemporânea. $3^{\text {a }}$ ed. Lisboa: Temas e Debates, 118-157. 